\title{
Material characterization of geopolymer mortar for its beneficial use in composite construction
}

\author{
Joachim Juhart ${ }^{1 *}$, Christopher Gößler ${ }^{2}$, Cyrill Grengg ${ }^{3}$, Florian Mittermayr ${ }^{1}$, Ognjen Rudic ${ }^{1}$, Andrew \\ McIntosh ${ }^{4}$, Bernhard Freytag ${ }^{2}$
}

${ }^{1}$ Institute of Technology and Testing of Construction Materials, Graz University of Technology
${ }^{2}$ Laboratory for Structural Engineering, Graz University of Technology, Austria
${ }^{3}$ Institute of Applied Geosciences, Graz University of Technology, Austria
${ }^{4}$ banah UK Ltd, Coleraine, N. Ireland

Received: 31 July 2020 / Accepted: 18 January 2021 / Published online: 05 February 2021

(C) The Author(s) 2021. This article is published with open access and licensed under a Creative Commons Attribution 4.0 International License.

\begin{abstract}
This paper investigates material properties of metakaolin/slag-based geopolymer mortar (GPM), relevant for composite action with conventional Portland cement-based concrete (PCC). GPM formulations with different workability (soft and stiff-plastic consistencies) were developed and characterized with regard to their compressive and tensile strength development over time, their shrinkage behaviour during hardening under different ambient conditions, as well as their thermal expansion. With the experimental data obtained, a coefficient of thermal expansion and equations for predicting the strength development were calculated. The GPMs exhibited significant autogenous shrinkage and drying shrinkage. Additionally, high very early shrinkage, tested by a new image correlation method, occurred immediately after setting under dry conditions. Thereby, the observed extent of early shrinkage strongly depended on the specimens' thicknesses. Furthermore, the basic characteristics of autogenous and drying shrinkage of GPM were enlightened and compared to PCC.
\end{abstract}

Keywords: Geopolymer mortar; Composite construction; Strength development; Autogenous, early and drying shrinkage; Coefficient of thermal expansion

\section{Introduction}

The deterioration of concrete structures due to the interaction with chemically aggressive solutions and gases is a major concern of the construction industry [1-3]. It is frequently observed that in waste and wastewater infrastructure ordinary Portland cement-based concrete (PCC) decomposes with high rates $(\sim 1 \mathrm{~cm} / \mathrm{a}$ under highly aggressive conditions [4-6]). Thus, alternative construction materials have to be found. In this context, alkali activated materials (AAM) - often also referred to as geopolymers (GP) in the literature - show great potential [7-16]. Compared to existing PCC construction materials, which are formed by the cement hydration reactions (mainly calcium hydroxide and calcium silicate hydrates), the AAM matrix is produced by polycondensation of alumino-silicates $[8-11,17,18]$. Thereby, alumina silicate powder materials (calcined clays, volcanic rocks, blast furnace slag, fly ash) are mixed with alkaline reagent solutions (either sodium or potassium soluble silicate) and water. This binder paste is further mixed with aggregates in order to form a material with similar mechanical properties as PCC. AAM technology avoids the formation of Ca-rich, acid-dissolvable hydration products, present in Ordinary Portland Cement (OPC) based materials. The absence of these phases is mainly responsible for the high acid resistance of AAM/geopolymer mortar (GPM) [5, 7, 9]. Furthermore, AAMs are a sustainable alternative to OPC based materials because of their lower $\mathrm{CO}_{2}$ emissions compared to PCC $[9,13]$.

Economic considerations and the use of GPM and concrete for repair measures of existing concrete infrastructure led to the idea of GPM - PCC composite structures. This composite technology seems to have a considerable market potential. The PCC - i.e. standardized normal concrete - provides the main part of the structural settings and the geopolymer acts as both, a structural part and a barrier against chemical attack. To develop such a new composite technology, material parameters of both, PCC and GPM have to be understood in detail. In general, composite constructions are built by bringing the fluid or pasty adhesive (GPM) into close and continuous contact to the solid adherent (PCC). The final mechanical strength of the adhesive interface depends mainly on (i) material properties of both adhesive and adherent (tensile strength, shear strength, thermal and hygric deformation coefficients etc.) and (ii) properties and pretreatment of the adherent's surface (roughness, open porosity, wettability etc.) [19]. If crack formation is decisive

\footnotetext{
* Corresponding author: Joachim Juhart, Email: joachim.juhart@tugraz.at
} 
for the bond strength, it will also depend on the development of the tensile strength of the adhesive over time $\left(f_{c t}(t)\right)$ and of internal stresses (enforcements $\sigma_{x}, \sigma_{y}, \tau_{x y}$ ). The latter occur during the hardening process of an adhesive due to constraints by the solid adherent [19-21], hindering shrinkage $\left(\varepsilon_{s}\right)$ or expansion of the adhesive. Driving forces are changes in temperature (if the thermal expansion of the bonding materials differs from each other), or autogenous and drying shrinkage of the adhesive during the hardening process. Restraint shrinkage/expansion can result in crack formation and/or can induce delamination starting at the edge of a cover layer in the interface, see Fig.1 and [22, 23].

Shrinkage or swelling is caused by a change in the water balance of a porous building material $[22,24]$. A distinction is made between (i) autogenous shrinkage (AS) due to chemical reactions during curing in combination with self-desiccation (i.e. loss of internal water through hydration [22, 25]) and (ii) drying shrinkage (DS) or swelling, which occurs due to the desiccation and adsorption of water under changing ambient conditions. DS depends strongly on temperature and relative humidity and the proportion of drying surface to the total volume. In contrast to AS, DS is partly reversible. Additionally, very early shrinkage (ES) occurs in fresh, still workable concrete. It is mainly activated by surface forces between the particles and water - capillary tension respectively - that increase with drying out of the pores system [20]. This type is also referred to as "plastic shrinkage" or "solidification shrinkage". It occurs on the surface and can cause cracks in the fresh concrete in the first few hours after mixing. Cracks in all cases occur if stress, induced by restrained shrinkage, exceeds the concrete's actual tensile strength [26]. However, cracks do not occur in a plastic state before setting has finished, as no stresses can be transferred into the matrix [27, 28]. Setting indicates, that fresh concrete is no longer plastically deformable. Shrinkage behaviour is reported to differ considerably for different types of cementitious materials, with significant differences between PCC and AAM, often showing a higher shrinkage of AAM compared to PCC
$[29,30]$. Even within the large group of AAM, there are large differences in shrinkage behaviour depending on the source materials and their mixing ratios [31-34]. Especially a higher drying shrinkage [29-36] is reported for ground granulated blast furnace slag (GGBFS) based AAM compared to fly ash based AAM. The degree of shrinkage of AAMs depends strongly on the ambient relative humidity $(\mathrm{RH})$, more than known from PCC. In particular, the point in time at which the maximum shrinkage rate (i.e. the gradient of the shrinkage strain curve over time) occurs varies strongly for pastes of GGBFS-AAM [30] when stored under different RHs. In contrast, the maximum shrinkage rate of OPC-pastes occurs in the first days of drying, regardless of prevailing $\mathrm{RH}$ [30]. In order to reduce AS and DS of AAMs, several mitigation strategies have been investigated $[37,38]$. Therein, the authors report, that combining two types of geopolymer raw materials, such as GGBFS and metakaolin (MK), may lead to potentially reduced shrinkage.

This study focuses on material properties of MK-rich calcined clay /GGBFS based GPM [39] in terms of strength development, shrinkage (using different shrinkage test setups) and the coefficient of thermal expansion. Results are compared with known shrinkage behaviour of PCC and are implemented in fundamental equations to predict GPM shrinkage behaviour and consistency-depending strength development with time.

\section{Materials and methods 2.1 GPM production}

GPM was produced by mixing metakaolin-rich calcined clay and GGBFS binder ("banahCEM", Table 1) with a potassium based fluid activator (waterglass). Siliceous sand $0 / 4 \mathrm{~mm}$ was added as aggregate. Two mixes with different consistencies (W-GPM/soft consistency for wet cast applications and DGPM/stiff-plastic for dry cast) were developed by varying the volumetric ratio of paste to aggregate (Table 2).

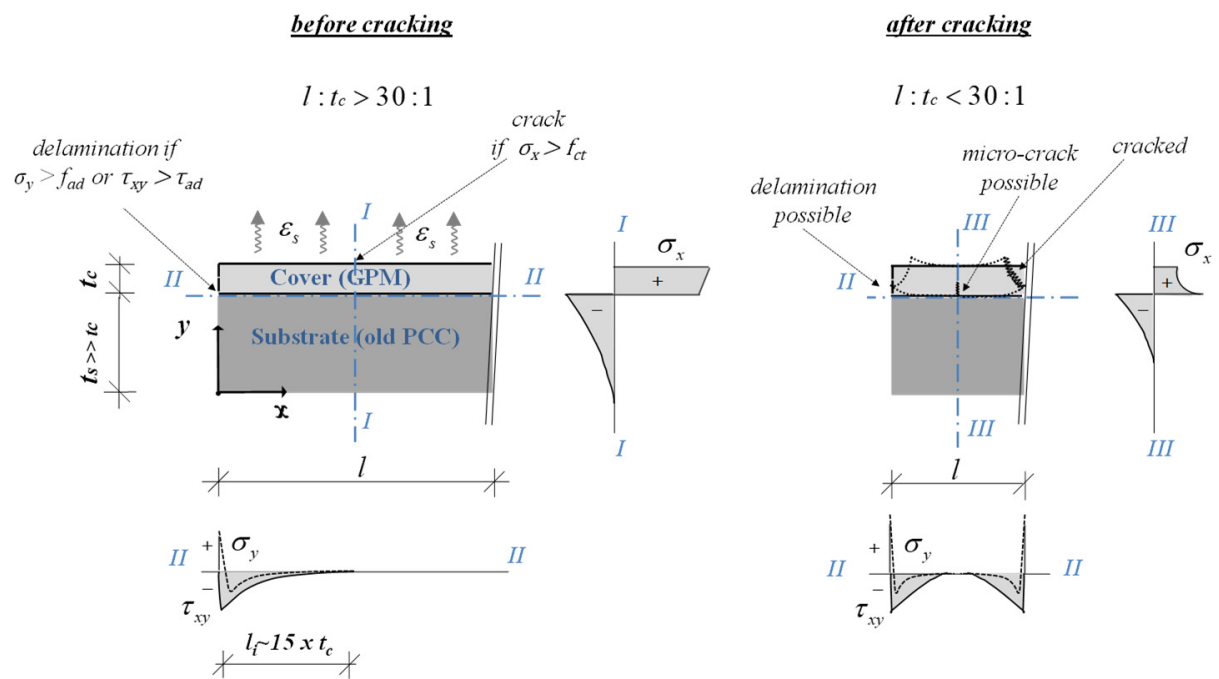

Figure 1. Stress distribution of enforcements $\left(\sigma_{x}, \sigma_{y}, \tau_{x y}\right)$ due to constrained hygric shrinkage $\left(\varepsilon_{s}\right)$ depending on ratio $I: t_{c}$ (extent : cover layer-

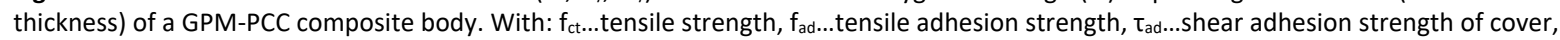
li....initiation length, modified after [23]. 
Table 1. Chemical composition of the metakaolin/GGBFS binder ("banahCEM") in wt.\%

\begin{tabular}{|l|l|l|l|l|l|l|l|l|}
\hline $\mathrm{SiO}_{2}$ & $\mathrm{Al}_{2} \mathrm{O}_{3}$ & $\mathrm{~K}_{2} \mathrm{O}$ & $\mathrm{CaO}$ & $\mathrm{Fe}_{2} \mathrm{O}_{3}$ & $\mathrm{MgO}$ & $\mathrm{Na}_{2} \mathrm{O}$ & $\mathrm{TiO}_{2}$ & $\mathrm{SO}_{3}$ \\
\hline 33.9 & 24.8 & 0.23 & 14.0 & 18.2 & 3.47 & 0.24 & 2.33 \\
\hline
\end{tabular}

Table 2. Composition and consistency of GPM

\begin{tabular}{|c|c|c|c|}
\hline & unit & $\operatorname{mix} W-G P M$ & mix D-GPM \\
\hline activator (waterglass, 35 wt.\% water content) & \multirow{4}{*}{$\mathrm{kg} / \mathrm{m}^{3}$} & 270 & 232 \\
\hline banahCEM & & 400 & 344 \\
\hline added water & & 121 & 104 \\
\hline crushed sand $0 / 4$ & & 1504 & 1663 \\
\hline paste volume & $1 / \mathrm{m}^{3}$ & 430 & 370 \\
\hline effective water/solid-ratio & - & 0.37 & 0.37 \\
\hline flow-table spread (without jolts/with jolts) & $\mathrm{mm}$ & $132 / 165$ & $100 / 115$ \\
\hline
\end{tabular}

Mix-volumes of 1.0 - 1.2 litres were prepared using a 4.5 । (total volume) planetary lab-mixer according to EN 196-1 [40]. For preparing larger batches (5 litres), i.e. to fill shrinkage troughs, a 10 I intensive compulsory mixer ("Eirich-RV10") was used. It consists of a rotating mixing container, an eccentrically arranged, counter-rotating high speed stirrer and a bottom-wall scraper. First, the activator and additional water were put into the mixer. Then the powder precursor was added during continuously mixing at the lowest possible speed for 3 minutes. Subsequently, the aggregates were added and mixed for another 2.5 minutes at the same speed. Finally, the mix was homogenized for half a minute at maximum speed.

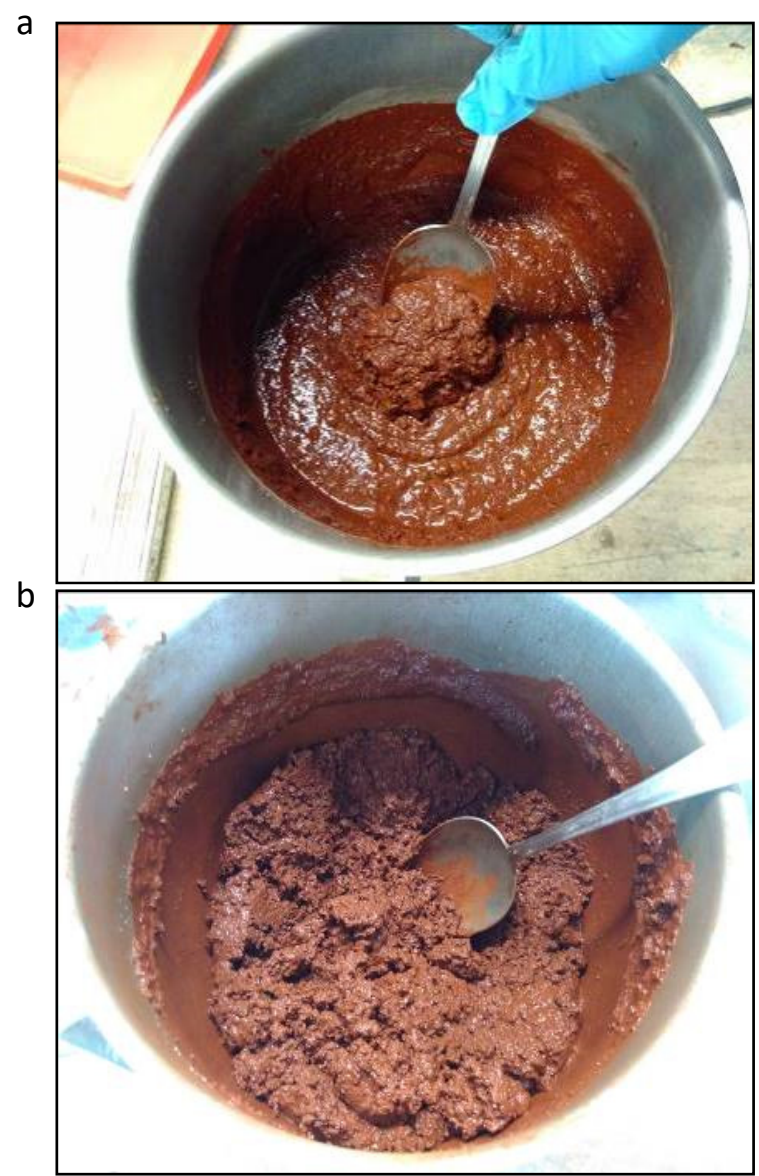

Figure 2. a) Wet-cast W-GPM and b) Dry-cast D-GPM immediately after mixing

\subsection{Consistency test of GPM}

To test the consistency of the GPM according to EN 1015-3 [41], the GPM mix was poured into a Hägermann cone ( $100 \mathrm{~mm}$ base diameter) on a dry glass plate of a compaction table. Thereafter, the cone was lifted to allow a free flow of the mortar. After two minutes, without applying any jolt, two perpendicular diameters of the concrete were measured. Subsequently, 15 jolts of the table were applied before diameters were measured again. For results, see Table 2 .

\subsection{Compressive and tensile strength development over time}

Prisms of 40/40/160 mm were manufactured of each GPM mix (soft consistency W-GPM and stiff-plastic D-GPM) and used for compressive strength tests $(n=3)$ according to EN 196-1 [40], as well as for splitting tensile strength tests $(n=4)$ according to ONR 23303 [42] (corresponding to EN 12390-6 [43]). The prisms were prepared and stored as follows: (i) compaction of the fresh GPM in plastic-moulds on a vibration table for about $1 \mathrm{~min}$, (ii) covering, using a plastic foil, (iii) storing the moulds in $>95 \%$ relative humidity $(\mathrm{RH})$ and $20^{\circ} \mathrm{C}$ for 3-5 hours, (iv) demoulding and (v) storing the prisms in $>95 \% \mathrm{RH}$ and $20^{\circ} \mathrm{C}$ until testing. Strength tests were carried out after $6 \mathrm{~h}, 24 \mathrm{~h}, 7 \mathrm{~d}$ and $28 \mathrm{~d}$. According to fib model code 2010 [44], the conversion factor of splitting tensile strength to (uniaxial) tensile strength is equal to 1.0, unless determined differently. This is also assumed to be valid for GPM used in this study. The dry densities of the two mixes were determined with prisms as normally done in the course of strength determination by weighing and calculating the volume using the dimensions of the prisms.

\subsection{Shrinkage during hardening under different conditions}

In order to characterize the shrinkage behaviour comprehensively, several test methods were applied on the two GPM mixes (W-GPM, D-GPM). They aimed to characterize material behaviour regarding (i) the autogenous shrinkage (AS), (ii) the hygric shrinkage or drying shrinkage (DS) under varying ambient humidity and (iii) the very early shrinkage (ES) obtained during rapid drying.

Autogenous shrinkage. AS was measured using stainless steel shrinkage troughs (Schleibinger shrinkage drain [45]) with the dimensions $40 / 60 / 1000 \mathrm{~mm}$. These were filled with fresh 
GPM immediately after mixing. Each trough was lined with a $2 \mathrm{~mm}$ thick rubber sheet and a plastic film, which acted as flexible intermediate layer, so that the GPM sample could move freely against the trough's bottom and walls (Fig. 3). The upper mortar surface was covered with the plastic foil. One end of the sample was anchored using a barbed hook as soon as the material gained a certain stiffness during hardening. At the other end a freely movable stamp was attached to the sample (using an anchor), so that an inductive transducer (resolution of $0.3 \mu \mathrm{m}$, accuracy of $<1 \mu \mathrm{m}$ ) was able to record the displacement, representing the change in length of the entire sample. Special attention was paid to activate the transducer before the setting of the material was completed. The sensor continuously recorded the length change of the GPM samples over a period of 17 days. A temperature sensor embedded in the middle of each sample recorded the GPM temperature. The troughs were placed in a room with defined climate conditions $\left(23^{\circ} \mathrm{C} \pm 2^{\circ} \mathrm{C}, 50 \% \mathrm{RH} \pm\right.$ $5 \%)$. AS was determined as the mean value of $3 \mathrm{~W}$-GPM samples and 2 D-GPM samples.

Drying shrinkage. DS was measured in this study using 2 different methods. Firstly, the shrinkage trough measurements described above were continued after the removal of the cover on the 7th day. Since then, the GPM were allowed to dry under ambient conditions $\left(23^{\circ} \mathrm{C}\right.$, $50 \% \mathrm{RH})$. Secondly, the length change of prisms $40 / 40 / 160 \mathrm{~mm}$ was determined according to EN 12617-4 [46]. Therefore, the prisms were manufactured as described above, with steel-markings embedded in the mortar at both ends. Prisms were demoulded after $3 \mathrm{~h}$. At this point the initial length of each prism was determined. Afterwards, the specimens $(n=6)$ were stored at high humidity of $>95 \% \mathrm{RH}$ and $20^{\circ} \mathrm{C}$. The shrinkage deformations were determined as the difference between the initial length and the length measurement at a certain time (after $6 \mathrm{~h}, 24 \mathrm{~h}, 48 \mathrm{~h}$ etc. until the end), divided by the initial length. As initial length the specimen's length minus half of the embedding length of the steel markings at each end $(160-2 * 6=148 \mathrm{~mm})$ was considered, according to EN 12390-16 [47]. After this period, the samples were stored for another 7 days at $23^{\circ} \mathrm{C}$ and $50 \%$ $\mathrm{RH}(\mathrm{n}=3)$ or at $20^{\circ} \mathrm{C}$ and $65 \% \mathrm{RH}(\mathrm{n}=3)$. During that period measurements of length change were continued. Thereafter,

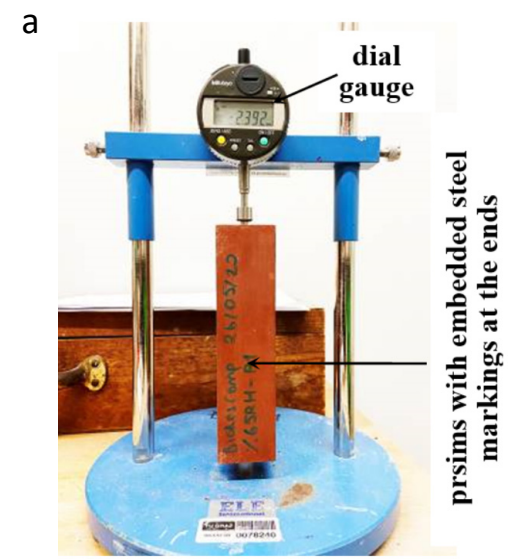

all specimens were stored again at $20^{\circ} \mathrm{C}$ and $>95 \%$ RH until the end of measurement.

In addition to the shrinkage measurements, the mass change $\Delta m$ of the prisms was determined by weighing immediately after each length measurement. The mass change is expressed as a percentage of the initial mass (i.e. mass after 3 h).

Very early shrinkage. Cylindrical specimens with four different thicknesses $(t=5,10,20$ and $40 \mathrm{~mm}$ ) and the same diameter $(\mathrm{d}=105 \pm 1 \mathrm{~mm})$ were made. These so called discs were produced pouring the GPM mixes into plastic rings of the respective heights. The rings were placed on a $2 \mathrm{~mm}$ thick rubber sheet to ensure free movement of the GPM. The bottom and the inner surface of the rings were waxed to avoid friction and to prevent the circumference sides of GPM from drying. Continuous vibration during casting ensured compaction. After casting, gauge marks were placed on the surface before the specimens were stored at $23^{\circ} \mathrm{C}$ and $50 \%$ $\mathrm{RH}$. Deformations of the specimens were measured by using an image correlation method (optical measuring equipment from manufacturer "Sobriety s.r.o." using the "Mercury RT" software [48]). Therein, two cameras take photographs from the samples at the same time. The software calculates the relative movements of the gauge marks, which are further recalculated into the shrinkage strains. The measurements were started at the setting time of the GPM and ran for 7 days. Fig. 4 shows the ES test set-up.

\subsection{Point in time of stress inducing setting}

As long as mortar or concrete is in a plastic state, shrinkage under external constraints does not lead to stress development. At a certain point during the setting process, a continuously solid body forms and the concrete reaches a level of stiffness, which is the reason for inducing tensile stresses. This time was determined as the point of maximum deformation rate in the AS measurements. It refers to as stress-inducing setting time $t_{s}[27,28]$. The time of "final setting" under dry conditions $t_{s, d r y}$ however, was measured additionally with the VICAT device (in accordance to EN 1963 [49]) in such a way, that the sample surface was exposed to drying under $65 \% \mathrm{RH}$ and $20^{\circ} \mathrm{C}$. b

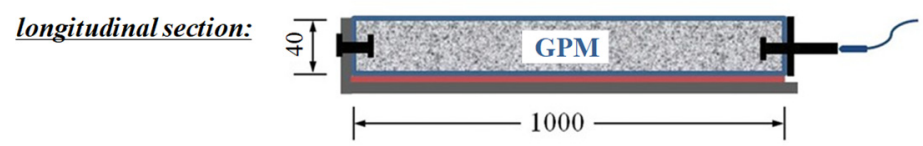

plan view:

dimensions in [mm] drawing not to scale

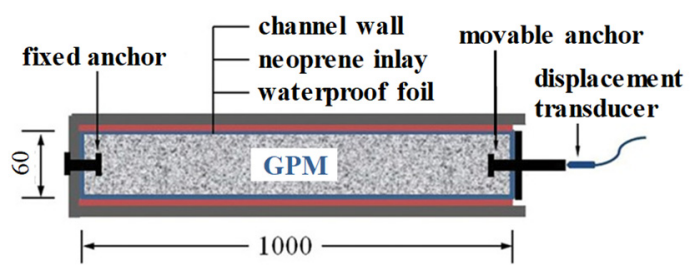

Figure 3. Set-up for the measurement of a) length change of prisms 40/40/160 mm according to EN 12617-4 [46] and b) shrinkage in a trough according to $[28,45]$. 
a

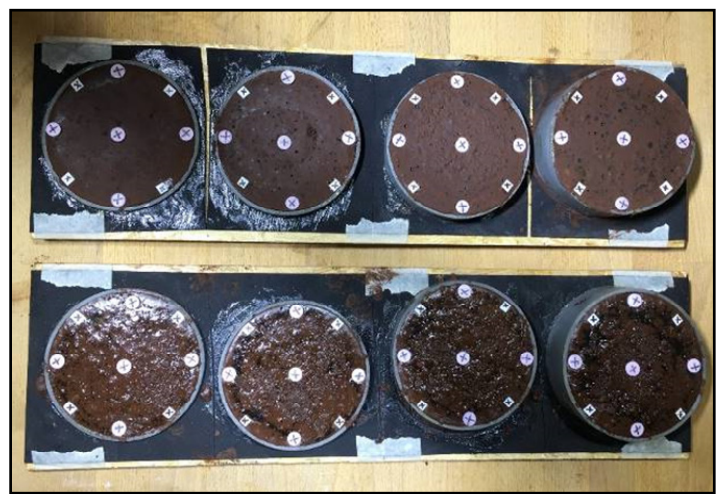

b

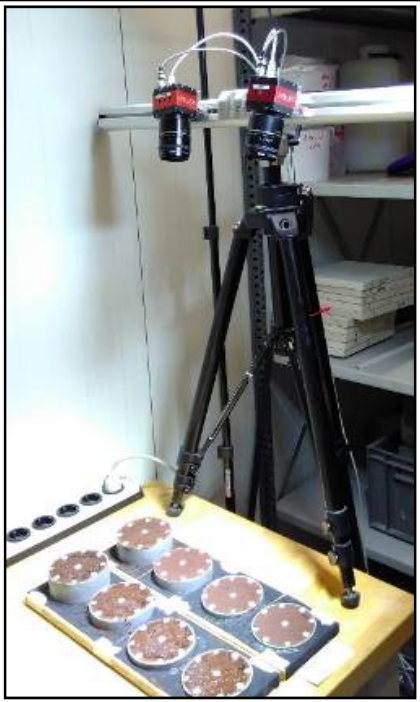

Figure 4. Very early shrinkage test: a) cylindrical specimens of mix WGPM (upper row), D-GPM (lower row), b) stereo-camera set up.

\subsection{Coefficient of thermal expansion}

The coefficient of thermal expansion $\alpha_{-20 / 40}$ of GPM was determined for a temperature range of $-20^{\circ} \mathrm{C}$ to $+40^{\circ} \mathrm{C}$ according to EN 1770 (alternative procedure) [50]. As aforementioned, prisms $(40 / 40 / 160 \mathrm{~mm})$ were manufactured with steel markings embedded at both ends; three prisms from each mix. After demoulding at $3 \mathrm{~h}$, they were stored friction-free for 21 days at $23^{\circ} \mathrm{C}, \mathrm{RH} 50 \%$ to ensure unhindered and complete drying. Thereafter, they were carefully wrapped with plastic foil to seal them during the following storage at different temperatures. Their change in length, when exposed to a sequence of temperatures of $23^{\circ} \mathrm{C}, 0^{\circ} \mathrm{C},-20^{\circ} \mathrm{C}, 40^{\circ} \mathrm{C}$ and $60^{\circ} \mathrm{C}$, was determined according to EN 1770 [50]. The individual measurements were carried out on three prisms of each mix (W-GPM and D-GPM). For each measurement, the test specimens were taken out of the climate chamber for a maximum of $1 \mathrm{~min}$ before their length change was determined. As initial length the specimen's length $(160 \mathrm{~mm})$ was considered, as specified in EN 1770 [50]. Measurements were carried out in $24 \mathrm{~h}$ intervals until length constancy at each step was achieved. In accordance to EN 1770 [50], only the range from $-20^{\circ} \mathrm{C}$ to $40^{\circ} \mathrm{C}$ was used to determine the coefficient of thermal expansion $\alpha_{20 / 40}$ by linear regression analysis.

\section{Results}

All presented properties are time-dependent. The time of mixing the powder into the fluid activator is considered as the starting point of the chemical reaction. It is therefore specified as "time zero" of the time axis in all presented plots.

\subsection{Point in time of stress inducing setting}

Setting time $t_{s}$ - relevant for stress-inducing stiffness of GPM was determined as $2.25 \mathrm{~h}$ after time zero for both mixes $\mathrm{W}$ GPM and D-GPM. This result is valid for sealed or high ambient humidity conditions (>95\% RH). In contrast, the setting time for a drying (unsealed) surface was determined as $\mathrm{t}_{\mathrm{s}, \mathrm{dry}}=1.2 \mathrm{~h}$.

\subsection{Compressive and tensile strength development over time}

Fig. 5 shows the development of the compressive strength $f_{c m}(t)$ and the tensile strength $f_{c t m}(t)$ of the GPM mixes W-GPM and D-GPM over time. The strength values of the two formulations do not differ significantly from each other. The $28 \mathrm{~d}$ compressive strength $f_{c m}$ reaches $61.5 \mathrm{~N} / \mathrm{mm}^{2}$ (as mean value of both mixes), with a tensile strength $f_{\mathrm{ctm}}$ of $5.3 \mathrm{~N} / \mathrm{mm}^{2}$. A fitting function for $f_{c m}(t)$ of GPM was computed by means of regression analysis on the basis of equation (1) [44].

$$
f_{c m}(t)=f_{c m} \cdot \exp \left\{s \cdot\left[1-\left(\frac{28}{t}\right)^{0.5}\right]\right\}
$$

Note that time $t$ is used in days and $f_{c m}$ is an input value of the equation. In particular, the coefficient $s$ has been recalculated. It stands for the strength class of the cement in the model code 2010 [44]. The regression analysis shows a high coefficient of determination $\left(R^{2}=0,998\right)$ and gives $s=0.07$ for the geopolymer binder under investigation. For the tensile strength $f_{c t m}(t)$ the same function works well for describing the development over time. In this case the $28 \mathrm{~d}$ tensile strength $f_{c t m}$ is used as input value (see equation (2)). The recalculation gives also $\mathrm{s}=0.07$ at the same level of accuracy $\left(R^{2}=0,998\right)$.

$$
f_{c t m}(t)=f_{c t m} \cdot \exp \left\{s \cdot\left[1-\left(\frac{28}{t}\right)^{0.5}\right]\right\}
$$

In Fig. 5 compressive and tensile strength development of the GPMs are compared to data of PCC. The PCC-data are taken from model code 2010 [44] exhibiting a $f_{c m}$ of $61.5 \mathrm{~N} / \mathrm{mm}^{2}$, which is the same $28 \mathrm{~d}$-strength as the GPM has. The tensile strength of the PCC $\left(f_{c t m}\right.$ of $\left.4.2 \mathrm{~N} / \mathrm{mm}^{2}\right)$ was calculated using the formula for tensile strength from a given compressive strength $f_{c m}$ over $50 \mathrm{~N} / \mathrm{mm}^{2}$ [44]. In that case $\left(f_{c m}>50 \mathrm{~N} / \mathrm{mm}^{2}\right)$, the coefficient $s$ has to be set to 0.2 . The $f_{\mathrm{ctm}} / f_{\mathrm{cm}}$ ratio is given by 0.087 of GPM at an age of $28 d$, that of PCC is 0.068 .

The dry densities of the two formulations were measured on the prisms before strength tests and did not differ significantly from each other, i.e. $2309 \mathrm{~kg} / \mathrm{m}^{3}$ of W-GPM and $2290 \mathrm{~kg} / \mathrm{m}^{3}$ of D-GPM as mean values of 6 specimens each. 

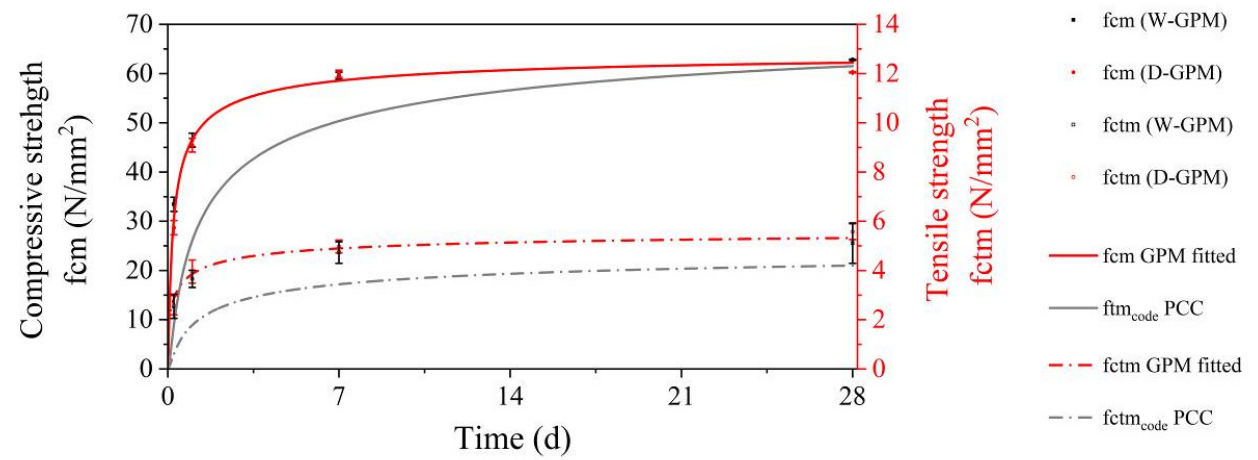

Figure 5. Compressive and tensile strength development of GPM versus normal concrete PCC according to model code 2010 (with standard deviation).

Time (d)

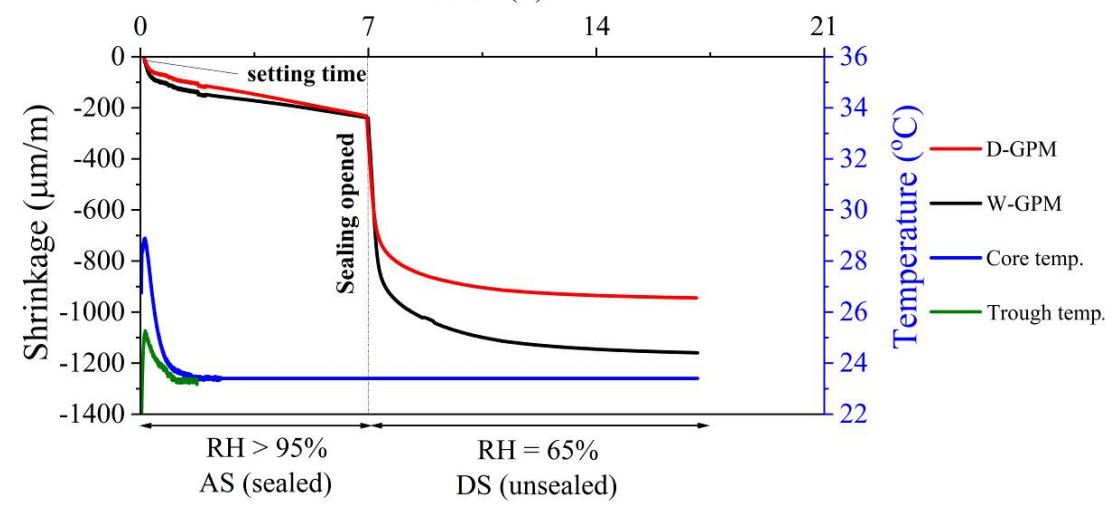

Figure 6. AS measured under sealed conditions in the first period (0-7 d); DS measured under $50 \%$ RH at $23{ }^{\circ} \mathrm{C}$ subsequently (7-17 d) with the unsealed shrinkage trough. Additionally, temperatures of GPM in the core of the specimens and of the inner bottom of the steel trough are shown.

\subsection{Shrinkage during hardening under different conditions}

AS and DS measured with the shrinkage trough. Fig. 6 shows the shrinkage strain development over time of the two GPM mixes. AS was measured under sealed conditions in the period from 0 to $7 \mathrm{~d}$. To show the pure shrinkage strain, the strain due to changes in temperature of the GPM during hardening, as well as the longitudinal deformation of the steel trough caused by its temperature changes were taken into account. In doing so, the core temperature of the GPM, the temperature of the steel trough at its inner bottom, the coefficient of thermal expansion of GPM at the age of $28 \mathrm{~d}$ (see chapter 2.6 and 3.5, i.e. $12 \cdot 10^{-6} \mathrm{~K}^{-1}$ ) and the coefficient of thermal expansion of stainless steel $\left(23 \cdot 10^{6} \mathrm{~K}^{-1}\right.$ according to [45]) were used. Since the coefficient of thermal expansion of the GPM at $28 \mathrm{~d}$ may differ from that at early age, this is considered a first approximation. However, the rise and fall in temperature during curing ends after 48 hours (see temperature curves in Fig. 6).

Within the first $24 \mathrm{~h}$ the samples W-GPM and D-GPM show very rapid shrinkage and reach nearly identical values of approximately $220 \mu \mathrm{m} / \mathrm{m}$ after $7 \mathrm{~d}$. After the removal of the sealant, higher shrinkage rates were observed for the $\mathrm{W}$ GPM. This DS happens very rapidly in the first few hours after the removal of the sealant. It asymptotically tends towards a maximum, which was not fully reached during the measuring period.

Total shrinkage (AS and DS) measured on prisms during changing ambient conditions. Similar results were obtained following the test setup described in EN 12617-4 [46] on prisms, on which the initial measurements were started very soon $(\sim 0,75 \mathrm{~h})$ after setting time $\mathrm{t}_{\mathrm{s}}$, see Fig. 7. During the initial storage $(0-7 \mathrm{~d})$ at $20^{\circ} \mathrm{C}$ and $\mathrm{RH}>95 \%$, an average shrinkage of $310 \mu \mathrm{m} / \mathrm{m}$ (W-GPM) and $200 \mu \mathrm{m} / \mathrm{m}$ (D-GPM) was measured. In the following period (7-14 d), 3 specimens of each mixture were stored at $23^{\circ} \mathrm{C}$ and $50 \% \mathrm{RH}$ and 3 specimens at $20^{\circ} \mathrm{C}$ and $65 \% \mathrm{RH}$. The rounded total shrinkage after $14 \mathrm{~d}$ was $1240 \mu \mathrm{m} / \mathrm{m}$ (W-GPM) and $1000 \mu \mathrm{m} / \mathrm{m}$ (D-GPM), regardless of whether shrinking took place at $50 \%$ or $65 \%$ (Fig. 7a). Interestingly, the obtained mass loss due to drying, was significantly higher for specimens stored at lower humidity ( $50 \% \mathrm{RH})$, compared to the ones stored at higher humidity (65\% RH) (Fig. 7b).

In the last period (14-25 d) all specimens were stored again at $\mathrm{RH}>95 \%$, which led to an expanding deformation. However, the expansion was less than the previous shrinkage, leaving an irreversible deformation after the cycle of desiccation and reabsorption of moisture. For the specimens exposed to lower $\mathrm{RH}$ conditions $\left(23^{\circ} \mathrm{C}, 50 \% \mathrm{RH}\right)$ higher irreversible deformation was observed (Fig. 7a). 

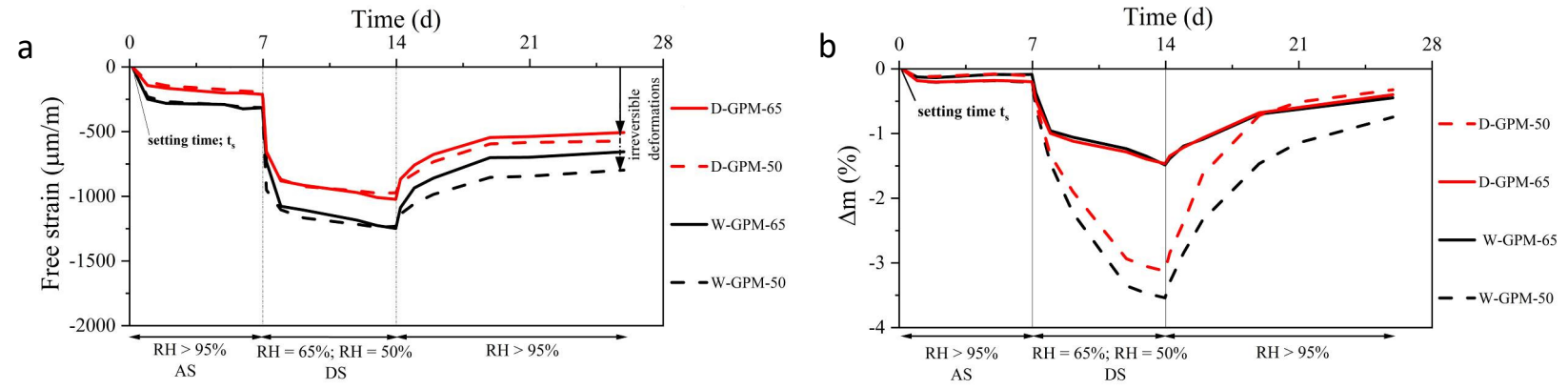

Figure 7. Hygric shrinkage and expansion during hardening under changing ambient conditions a) free strain and b) mass change $\Delta \mathrm{m}$. In the first period (0-7 d) all samples were stored at $20^{\circ} \mathrm{C}$ and RH $>95 \%$. In the second period (7- $14 \mathrm{~d}$ ), 3 samples of each mixture, W-GPM as well as D-GPM, were stored at $23^{\circ} \mathrm{C}$ and $50 \% \mathrm{RH}$ and 3 samples at $20^{\circ} \mathrm{C}$ and $65 \% \mathrm{RH}$. In the last period (14-25 d), the samples were all stored at $\mathrm{RH}>95 \%$.

Time (h)

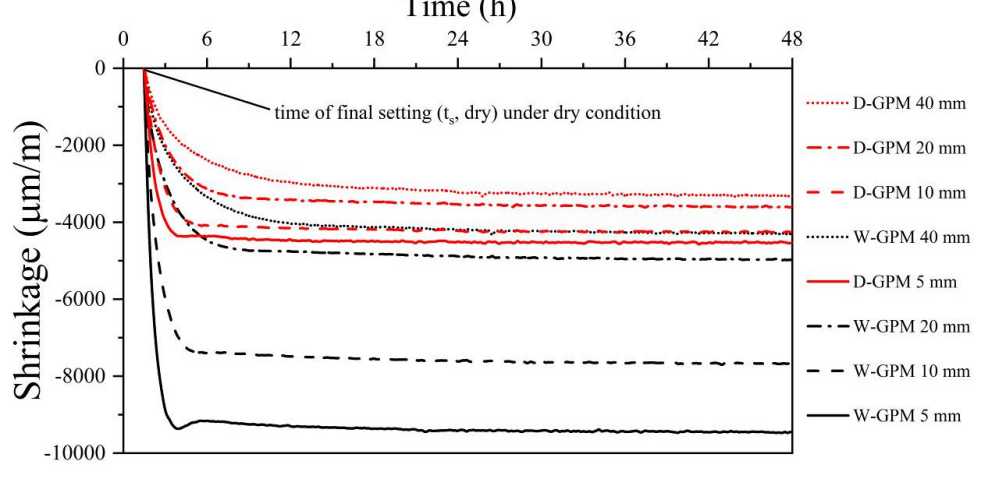

Figure 8. Shrinkage strains due to very early drying of freely moveable layers with different thickness of the wet-cast (W-GPM) and dry-cast mix (D-GPM). Layers were exposed to $23^{\circ} \mathrm{C}$ and $50 \% \mathrm{RH}$ from time of setting on under dry conditions for the first $48 \mathrm{~h}$.

Table 3. Mean values, standard deviation and coefficient of variation of shrinkage strains of disc specimens acquired by DIC system at the time of $48 \mathrm{~h}$ of measurement.

\begin{tabular}{|c|c|c|c|c|c|c|c|c|c|}
\hline \multirow[b]{2}{*}{ thickness } & \multirow[b]{2}{*}[\mathrm{mm}]{} & \multicolumn{4}{|c|}{ W-GPM } & \multicolumn{4}{|c|}{ D-GPM } \\
\hline & & 5 & 10 & 20 & 40 & 5 & 10 & 20 & 40 \\
\hline shrinkage at $48 \mathrm{~h}$ (mean of 4 diameters) & {$[\mu \mathrm{m} / \mathrm{m}]$} & -9444 & -7660 & -4965 & -4283 & -4512 & -4255 & -3609 & -3306 \\
\hline standard deviation & {$[\mu \mathrm{m} / \mathrm{m}]$} & 850 & 373 & 38 & 116 & 126 & 286 & 117 & 32 \\
\hline coefficient of variation & $\%$ & 9.0 & 4.9 & 0.8 & 2.7 & 2.8 & 6.7 & 3.3 & 1.0 \\
\hline
\end{tabular}

\subsection{Very early shrinkage under dry ambient conditions}

Fig. 8 shows the shrinkage strain curves over time of the disc specimens with different thicknesses and constant diameter as a result of surface drying at $23^{\circ} \mathrm{C}$ and $50 \% \mathrm{RH}$. Initial deformation started after $1.4 \mathrm{~h}$, which approximately corresponds to the time of the final setting of the GPM material $\left(\mathrm{t}_{\mathrm{s}, \mathrm{dry}}=1.2 \mathrm{~h}\right)$. Considerable higher reduction in diameter and associated higher shrinkage rates were observed for the thin discs, compared to the thicker ones. Additionally, higher shrinkage was observed on W-GPM specimens, exhibiting higher paste volume, compared to the D-GPM specimens with lower paste volume. After the high shrinkage rates during the first few hours, no significant further shrinkage with time can be observed. It is noteworthy that the shrinkage strains of the thinnest specimens after 24 $\mathrm{h}$ were characterized as about $9000 \mu \mathrm{m} / \mathrm{m}$ for W-GPM and $4500 \mu \mathrm{m} / \mathrm{m}$ for D-GPM, which is more than 30 times the shrinkage strains of the sealed specimens tested in the shrinkage trough test setup at $>95 \% \mathrm{RH}(100-300 \mu \mathrm{m} / \mathrm{m})$.
In Table 3 the mean value, standard deviation and coefficient of variation (COV=standard deviation/mean value) of the measured strains of the four diameters acquired by the DIC system are given. A higher scattering is observed within the first hours of the measurement (single values of COV up to twice), settling after $48 \mathrm{~h}$. The values after 48 hours are given in Table 3.

\subsection{Coefficient of thermal expansion}

The coefficient of thermal expansion of W-GPM was determined to be nearly equal to that of D-GPM by linear regression analysis with $\alpha_{-20 / 40}=12 \cdot 10^{-6} \mathrm{~K}^{-1}$ (within the specified temperature range of EN 1770 of $-20^{\circ}$ to $40^{\circ} \mathrm{C}$ ), Fig. 9. Table 4 shows the coefficients of the individual temperature steps. In the range of $-20^{\circ}$ to $40^{\circ} \mathrm{C}$ they deviate less from each other, while above $40^{\circ} \mathrm{C}$ to $60^{\circ} \mathrm{C}$ the coefficient decreases slightly. 


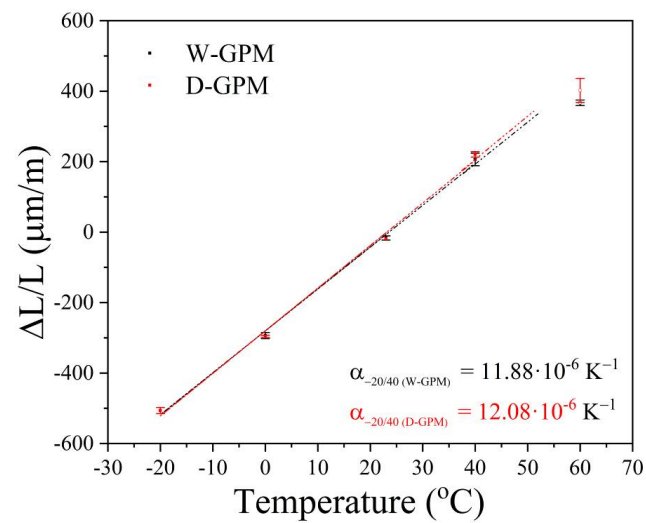

Figure 9. Thermal expansion $\Delta \mathrm{L} / \mathrm{L}$ depending on temperature and coefficient of thermal expansion $\alpha$-20/40.

Table 4. Coefficient of thermal expansion $\alpha$ in different temperature ranges and coefficient $\alpha$-20/40 according to EN 1770 [50] by regression analysis as well as its coefficient of determination $\mathrm{R}^{2}$

\begin{tabular}{|l|l|l|}
\hline & W-GPM & D-GPM \\
\hline Temperature range $\left({ }^{\circ} \mathrm{C}\right)$ & $\alpha\left(\mathrm{K}^{\left.-1 / 10^{-6}\right)}\right.$ & $\alpha\left(\mathrm{K}^{\left.-1 / 10^{-6}\right)}\right.$ \\
\hline$-20-0$ & 12.05 & 12.05 \\
\hline $0-23$ & 10.62 & 10.52 \\
\hline $23-40$ & 11.88 & 12.12 \\
\hline $40-60$ & 8.96 & 9.06 \\
\hline $\begin{array}{l}\text { Coefficient of thermal expansion by } \\
\text { regression analysis }\left(\alpha_{-20 / 40}\right)\end{array}$ & 11.88 & 12.08 \\
\hline $\begin{array}{l}\text { Coefficient of determination } \mathrm{R}^{2} \text { for } \\
\left(\alpha_{-20 / 40}\right)\end{array}$ & 0.998 & 0.996 \\
\hline
\end{tabular}

Following the procedure of EN 1770 [50] (i.e. putting sealed specimens successively under temperatures of $23^{\circ} \mathrm{C}$, $0^{\circ} \mathrm{C},-20^{\circ} \mathrm{C}, 40^{\circ} \mathrm{C}$ and $60^{\circ} \mathrm{C}$ and measuring the length change since it reaches stable values), a change in thermal expansion over time has not been noticed.

\section{Discussion}

\subsection{Compressive and tensile strength development over time}

Fig. 5 clearly shows, that the strength development of the GPM materials differs significantly compared to PCC (OPCbased). After 3 hours, GPM reaches 50\%, after $24 \mathrm{~h} 77 \%$ and after $7 d 95 \%$ of its $28 d$ value. Despite the varied paste volume used, low variations in compressive and splitting tensile strength between the two GPM mixes with constant water/solid ratio are observed. Strength of the presented GPM formulations developes much faster at early age compared to a typical PCC [44] with equal $28 \mathrm{~d}$ strength. The $f_{c t m} / f_{c m}$ ratio of GPM (=0.087) was significantly higher (by $27 \%$ ) compared to the PCC $(=0.068)$ from the model code 2010. Among the wide variety of possible formulations of AAM and especially GPM, such results are in agreement with existing literature $[8,9,51]$.

To some extent, the observed differences between the GPM and PCC may be due to "size effects" of mortar compared to concrete. The used formula of the model code 2010 is designed for concretes that generally have a larger maximum grain size and lower hardened paste volume than mortars (our GPM has a maximum aggregate size of $4 \mathrm{~mm}$ ).
Additionally, PCC is tested on cylindrical specimens instead of prismatic ones as used for GPM. This may result in scaling effects. However, these should be approximately constant over all test ages. Since GPM is compared here with PCC of the same $28 \mathrm{~d}$ compressive strength, the apparent difference in strength development up to $28 \mathrm{~d}$ cannot be attributed to "scale effects". The differences within the hardening process of GPM and PCC is therefore primarily associated with the reaction kinetics of the different binders used (presented GPbinder vs. OPC). For the outlined GPM a binder coefficient $s=0.07$ was determined by regression analysis whereas a coefficient $s$ of 0.2 is given in the model code 2010 for OPC (regarding concrete strength classes $>\mathrm{C} 50 / 60$ ). The results demonstrate that the formula given in the model code 2010 [44] can thus be applied to describe the strength development of GPM over time, if the binder coefficient $s$ is adapted. Further investigations, such as tests with modified maximum grain size over a longer period of time and/or tests recognizing other influences (geopolymer formulation, influence of storage conditions etc.) are needed to further strengthen that conclusion.

\subsection{Shrinkage during hardening under different conditions}

AS of the GPM, tested in the shrinkage trough at $\mathrm{RH}>95 \%$ is very pronounced in the first $24 \mathrm{~h}$. Thereafter, shrinkage rates decrease significantly, approaching nearly identical values after $7 \mathrm{~d}$ of $\sim 220 \mu \mathrm{m} / \mathrm{m}$, Fig. 7a. A potentially incomplete sealing of the specimens in the shrinkage trough and the $\mathrm{RH}$ fluctuation of $95-99 \%$ of the prisms in the storing chamber within the AS measuring period (0-7 days) might have caused a slight overestimation of AS due to the drying effect. Nevertheless, the values are higher than for Portland cement based mortar and concrete as also stated in [35] and are in the range of ultra high performance concrete (UHPC), which is known for its high AS [23].

The DS, which was measured in two measuring arrangements (shrinkage trough and prisms) until an age of $7 \mathrm{~d}$, is also found to be very pronounced. The drying shrinkage-rate, i.e. gradient of the DS curve, is initially extremely high, which means that there is rapid drying within the first hours of the investigated period (Fig. 7a). Higher total DS is observed on the W-GPM specimens, exhibiting a higher paste volume, compared to D-GPM (produced with a lower paste volume).

Fig. 10 presents the evolution of free strains (shrinkage and expansion) vs. mass change $(\Delta \mathrm{m})$ of the prisms exposed to different RH. Interestingly, the two different RH conditions (50\% and $65 \%$ ) resulted in almost equal maximum shrinkage strains for each mix, but different moisture loss. A moisture reduction from $>95 \% \mathrm{RH}$ to $65 \% \mathrm{RH}$ results in the same volume changes as when reduced to $50 \% \mathrm{RH}$. This means that the drying of the presented GPM only leads to increasing shrinkage deformations up to a specific moisture content. This is about $65 \% \mathrm{RH}$ or an even higher RH. The exact critical value of $\mathrm{RH}$ should be determined in future work. However, lower RH (than the critical value) leads to less drying shrinkage, as reported in literature for various slag-based alkali activated materials formulations [30-36]. Drying 
shrinkage is therefore not proportional to water loss, which is in contrast to the common understanding of Portland cement based materials $[52,53]$.

In the case of water absorption (or re-wetting), the presented GPM formulations re-expand, showing a hysteresis to the drying curve (Fig. 10). They no longer reach the initial length, i.e. an irreversible shortening remains (Fig. 7). The specimens exposed to dryer condition $\left(23^{\circ} \mathrm{C}, 50 \% \mathrm{RH}\right)$ exhibit larger irreversible deformation and mass change, compared to the ones exposed to higher humidity levels $\left(20^{\circ} \mathrm{C}, 65 \% \mathrm{RH}\right)$.

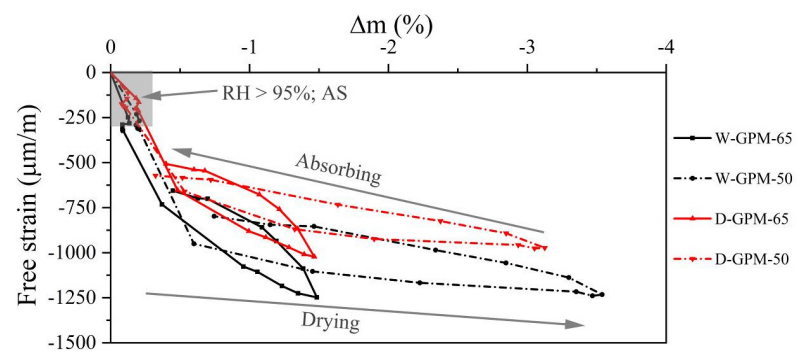

Figure 10. Free strains (shrinkage and expansion) vs mass variation (loss or gain) during length change measurements on prisms under different $\mathrm{RH}$.

The high drying shrinkage strains and shrinkage rates in alkali activated slag-based mortars and concretes are well documented [28-38, 53], but the exact reasons for this behaviour are still subject of research. The pore structure has a significant effect on drying shrinkage in AAM and differs to that of PCC. Possible explanations therefore are as follows: Increased drying shrinkage of AAM can be attributed to the finer overall porosity compared to that of OPC based materials, thereby, the finer pores increase the capillary tensile stress resulting in higher shrinkage rates [36, 51, 52]. Initial drying is assumed to lead to a structural change at the nano/microstructural level during the formation of the "geo"polymeric network [30, 35, 52, 53]. The drying shrinkage strain is not directly related to the water loss [30, 52]. Consistently, Collins et al. [36] argued that the pore structure is more important in determining the shrinkage of slag-based AAM concrete than the water loss. Ye et al. [37, 54, 55] concluded that the main driving force for slag based AAM shrinkage at high $\mathrm{RH}(>50 \%)$ is capillary pressure and high visco-elastic/visco-plastic compliance (i.e. low E-modulus and creep modulus). Thomas et al. [52] stated, that above $45 \% \mathrm{RH}$ capillary pressure and disjoining pressure are decisive but below $45 \% \mathrm{RH}$ other effects like surface energy effects are significant for shrinkage in porous materials and therefore also in AAM. Concluding, we attribute the high drying shrinkage values and rates compared to normal strength PCC to (i) a higher overall porosity, (ii) finer capillary pores with higher capillary tension and (iii) low E-modulus and creep modulus, creep effects respectively (which has to be investigated). Additionally, the role of pore connectivity remains to be clarified.

The tests of early drying shrinkage on specimens of different thicknesses revealed that thin layers shrink more and faster, compared to thick layers. This confirms that the deformation is directly related to superficial desiccation. While the surface dries and shrinks, the inner part of a thicker layer does not, or to a lower extent. Thus, the inner part acts similar to a rigid body, hindering the surface layer from shrinking. Accordingly, on the surface of the $40 \mathrm{~mm}$ thick disc of W-GPM very fine ( $<0.1 \mathrm{~mm}$ wide), branched cracks were visible (Fig. 11). Some sporadic cracks could also be detected on the $40 \mathrm{~mm}$ D-GPM sample, as well as on the $20 \mathrm{~mm} \mathrm{W-GPM} \mathrm{disc.} \mathrm{However,} \mathrm{the}$ $20 \mathrm{~mm}$ thick sample of D-GPM remained intact, as well as all thin specimens ( 5 and $10 \mathrm{~mm}$ ). It thus can be concluded that the W-GPM mix is slightly more susceptible to cracking compared to the D-GPM mix. This can further be attributed to its larger paste volume. Although the crack pattern visible on the $40 \mathrm{~mm} \mathrm{~W}$-GPM is not strongly pronounced, it fits very well to the theoretic knowledge about drying mechanisms and their corresponding cracking behaviour [20,56, 57]. Theoretically, under the condition of homogeneous shrinkage and homogeneous material, hexagonal crack fields, similar to a honeycomb structure, develop in a (infinitely extended) shrinking layer, if the deformation of the layer is hindered and its tensile strength is exceeded. A hexagonal crack pattern $\left(120^{\circ}\right.$ angle between the cracks) results because the requirement for the smallest crack-surface area (circumference of the crack field multiplied by crack depth) in relation to the enclosed volume is fulfilled. I.e. a minimum of new surface per unit volume is formed $[57,58]$. This crack pattern can be seen in rudimentary form on the $40 \mathrm{~mm}$ thick disc, Fig. 11.

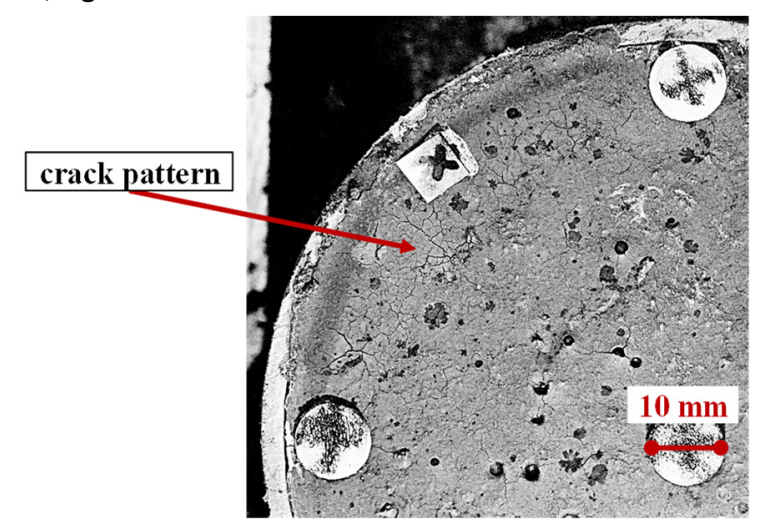

Figure 11. Detail of the surface of the W-GPM $40 \mathrm{~mm}$ disc with very fine drying cracks.

In order to get shrinkage values, which are not effected by thickness-depending moisture distribution, one has to minimise the thickness of the specimens tested. This was indeed the initial motivation for designing the outlined special test setup. It allows to measure the elementary, unhindered shrinkage behaviour on thin layers. The latter will be needed as an important input parameter for detailed finite element simulations of the early age composite action, for example in the production stage of GPM-PCC-Composite structures.

\subsection{Coefficient of thermal expansion}

The coefficient of thermal expansion $\alpha_{-20 / 40}=12 \cdot 10^{-6} \mathrm{~K}^{-1}$ of GPM is in the range of values found for concrete with different aggregates in the literature [24]. The design value of PCC according to fib model code [44] with $10 \cdot 10^{-6} \mathrm{~K}^{-1}$ is also in this range. The coefficient is practically the same for W-GPM and $\mathrm{D}-\mathrm{GPM}$ in the range $-20^{\circ} \mathrm{C}$ to $40^{\circ} \mathrm{C}$. Above $40^{\circ} \mathrm{C}$ it decreases slightly for both formulations. The similarity of the coefficient 
of thermal expansion of GPM and PCC is advantageous for the composite action of GPM and PCC.

\section{Conclusion}

In the context of the beneficial use of GPM in composite construction, two GPM-mixes (based on metakaolin-rich calcined clay, GGBFS and a potassium based fluid activator) with different consistencies were investigated with respect to their strength development and their shrinkage behaviour. The strengths of the presented GPM formulations develop much faster in the first few hours than those of PCC, allowing for early load bearing capacity. The strength development of GPM seems to have essentially reached its final value after $28 \mathrm{~d}$, which is in clear contrast to PCC. Results showed that the function given in the model code 2010 calculating the strength of PCC over time may also be used for GPM. The much faster hardening of the GPM can accurately be considered by adjusting the coefficient $s$ only, reflecting the influence of the binder.

It is shown that the investigated GPM exhibits both, significant AS and DS. Larger shrinkage deformations occur in the mixture with a larger volume of paste and softer consistency (W-GPM) compared to the mix with lower volume of paste (D-GPM). AS is very pronounced and rapid in the first $24 \mathrm{~h}$, which is in contrast to the shrinkage behaviour known from PCC. The DS, which was measured following the AS after $7 d$ on the same specimens by changing the ambient conditions was also very pronounced and showed high shrinkage rates within the first hours of drying. It is not fully reversible. At rather dry ambient conditions ( $\mathrm{RH} 50 \%$ ) less drying shrinkage occurred compared to higher RH (65\% RH). This observation agrees with literature results for various slagbased alkali activated materials formulations [30-36, 54, 55].

In addition, very rapid early drying shrinkage (ES) occurs immediately after exposition of GPM to drying. Its extent depends on the drying rate which is strongly influenced by specimens' thickness. In relatively thick test specimens, moisture is continuously transported from the inside to the outer layers. Consequently, the test on the thin layer reflects the elementary shrinkage behaviour, because the drying process is almost uniform over the entire volume.

Since the coefficient of thermal expansion of GPM does not differ significantly from that of PCC, internal stress in the bonding interface caused by changes in temperature will be manageable.

As the pronounced and fast shrinkage of GPM layers is usually hindered in the manufacturing process of composite constructions, crack formation is very likely to happen. A suitable way of preventing shrinkage cracks is to delay shrinkage by appropriate curing measures during the early phase of hardening (primarily by a drying protection). However, this is only effective if the enforcements due to restraint shrinkage will relax in this curing period.

\section{Outlook and acknowledgement}

Further testing and evaluation has to be done in an ongoing research project (granted under NR. 871279 of Austrian research promotion agency FFG). The creep and relaxation behaviour of GPM under tensile stress as well as the Emodulus over time, the influence of the surface texture of the adherent etc. need to be explored. For a deeper understanding, further investigations on DS under different $\mathrm{RH}$ and of the correlation of microstructural properties of GPM to its shrinkage is pending to be carried out.

We thank the companies banah UK Ltd, TIBA Austria GmbH and MM Kanalrohr-Sanierungs-GmbH for their kind support. The authors would like to thank Prof. G. Koraimann and colleagues from the Institute of Molecular Biosciences at the University of Graz for their expert support.

\section{CRediT authorship statement}

J. Juhart: Conceptualization, Methodology, Data Curation, Formal analysis, Validation, Writing-original draft, Writing review and editing, Visualization, Funding acquisition.

C. Gößler: Investigation, Data Curation, Formal analysis, Visualization.

C. Grengg: Methodology, Writing - review and editing, Funding acquisition.

F. Mittermayr: Writing - review and editing, Supervision, Funding acquisition.

O. Rudic: Investigation, Data Curation, Formal analysis, Visualization.

A. McIntosh: Resources, Writing - review and editing.

B. Freytag: Conceptualization, Methodology, Writing -review and editing, Supervision, Project administration, Funding acquisition.

\section{References}

[1] M. Alexander, A. Bertron, N. De Belie, Performance of Cement-Based Materials in Aggressive Aqueous Environments. 1st ed., Springer, Ghent (2013). https://doi.org/10.1007/978-94-007-5413-3

[2] M.W. Kiliswa, K.L. Scrivener, M.G. Alexander, The corrosion rate and microstructure of Portland cement and calcium aluminate cementbased concrete mixtures in outfall sewers: A comparative study. Cem Concr Res (2019) 124. https://doi.org/10.1016/j.cemconres.2019.105818

[3] M. Peyre Lavigne, A. Bertron, L. Auer, et al., An innovative approach to reproduce the biodeterioration of industrial cementitious products in a sewer environment. Part I: Test design. Cem Concr Res (2015) 73 : 246-256. https://doi.org/10.1016/j.cemconres.2014.10.025

[4] C. Grengg, F. Mittermayr, A. Baldermann, et al., Microbiologically induced concrete corrosion: A case study from a combined sewer network. Cem Concr Res (2015) 77: 16-25. https://doi.org/10.1016/j.cemconres.2015.06.011

[5] C. Grengg, F. Mittermayr., N. Ukrainzcyk. et al., Advances in mineral based construction materials for sewer systems affected by microbiological induced concrete corrosion: A review. Water Res (2018) 134: 341-352. https://doi.org/10.1016/j.watres.2018.01.043

[6] B. Druga, K. Weise, N. Ukrainzcyk, et al., Interaction of wastewater microorganisms with geopolymer and cementitious materials. In: Microorg Mater Interact RILEM (2018) 163-172.

[7] F. Pacheco-Torgal, Z. Abdollahnejad, S. Miraldo et al., An overview on the potential of geopolymers for concrete infrastructure rehabilitation. Constr Build Mater (2012) 36: 1053-1058. https://doi.org/10.1016/i.conbuildmat.2012.07.003

[8] F. Pacheco-Torgal, J. Labrincha, C. Leonelli et al., Handbook of AlkaliActivated Cements, Mortars and Concretes, 1st Edition. Woodhead Publishing (2014). https://doi.org/10.1533/9781782422884.1

[9] J.L. Provis, Alkali-activated materials. Cem Concr Res (2018) 114: 4048. https://doi.org/10.1016/j.cemconres.2017.02.009

[10] J.L. Provis, J.S.J. van Deventer, Alkali-activated materials: state-of-theart report. RILEM TC 224-AAM. Springer, Dordrecht (2014). https://doi.org/10.1007/978-94-007-7672-2

[11] J. Davidovits, Geopolymer Chemistry and Applications, 4th ed. Springer (2013) 
[12] C. Shi, P.V. Krivenko, D.M. Roy, Alkali-activated cements and concretes. Taylor \& Francis, Abingdon, UK. (2006) https://doi.org/10.4324/9780203390672

[13] M.C.G. Juenger, F. Winnefeld, J.L. Provis, J. Ideker, Advances in alternative cementitious binders. Cem Concr Res (2011) 41: 12321243. https://doi.org/10.1016/j.cemconres.2010.11.012

[14] J.S.J. Van Deventer, J.L. Provis, P. Duxson, Technical and commercial progress in the adoption of geopolymer cement. Miner Eng (2012) 29: 89-104. https://doi.org/10.1016/j.mineng.2011.09.009

[15] K. Arbi, M. Nedeljković, Y. Zuo, G. Ye: A Review on the Durability of Alkali-Activated Fly Ash/Slag Systems: Advances, Issues, and Perspectives. Industrial \& Engineering Chemistry Research (2016) 55: 5439-53 https://doi.org/10.1021/acs.iecr.6b00559

[16] S. Bernal, J.L. Provis, Durability of Alkali-Activated Materials: Progress and Perspectives. J Am Ceram Soc (2014) 97: 997-1008. https://doi.org/10.1111/jace.12831

[17] D. Dimas, Giannopoulou I., Panias D.: Polymerization in sodium silicate solutions: A fundamental process in geopolymerization technology. J Mater Sci (2009) 44: 3719-3730. https://doi.org/10.1007/s10853-009-3497-5

[18] N. Belmokhtar, M. Ammari, J. Brigui, L.B. Allal, Comparison of the microstructure and the compressive strength of two geopolymers derived from metakaolin and an industrial sludge. Constr Build Mater (2017) 146: 621-629. https://doi.org/10.1016/i.conbuildmat.2017.04.127

[19] J. Juhart, B. Freytag, G. Santner, E. Baumgartner, Adhesion of finegrained HPC and UHPC to Steel and Glass. In: Ultra-High Performance Concrete and Nanotechnology in Construction, Proc. Schriftenreihe Baustoffe und Massivbau, Vol. 19, Kassel University Press, Kassel (2012) 717-724

[20] J. Bisshop, Drying shrinkage Cracking at Early Ages, in: A. Bentur, Early age cracking in cementitious systems: Report of RILEM Technical Committee 181-EAS 'Early Age Shrinkage Induced Stresses and Cracking in Cementitious Systems'. Bagneux: RILEM Publ. RILEM report, 25 (2003).

[21] P. M. D. Santos, E. N. B. S. Julio, Factors affecting bond between new and old concrete. ACI Mater J (2011) 108(4): 449-456.

[22] D.P Bentz, A review of early age properties of cement-based materials. Cem Concr Res (2008) 38: 196-204. https://doi.org/10.1016/i.cemconres.2007.09.005

[23] J. Juhart, Adhäsion von UHPC an Stahl und Glas. Ein Beitrag zu Adhäsion und Haftfestigkeit von Hochleistungs- und UltraHochleistungs-Feinkornbeton an Stahl und Glas unterschiedlicher Rauheit. Dissertation, Graz University of Technology (2011). URL: https://graz.pure.elsevier.com/en/publications/adhesion-of-uhpcto-steel-and-glass

[24] A.M. Neville, J.J. Brooks, Concrete Technology, Addison Wesley Longman, Harlow, 2001.

[25] J. Ma, F. Dehn, G. König, Autogenous Shrinkage of self-compacting ultra-high performance concrete (UHPC), in Y. Yuan, S. P. Shah, H. Lü, (Hg.): Proc. International Conference on Advances in Concrete and Structures (ICACS). Xuzhou, Jiangsu/China, 2003.

[26] F. Kanavaris, M. Azenha, M. Soutsos, K. Kovler: Assessment of behaviour and cracking susceptibility of cementitious systems under re-strained conditions through ring tests: A critical review. Cem Concr Compos (2019) 95: 137-153. https://doi.org/10.1016/j.cemconcomp.2018.10.016

[27] M. S. Meddah, A. Tagnit-Hamou, Evaluation of Rate of Deformation for Early-Age Concrete Shrinkage Analysis and Time Zero Determination. J Mater Civ Eng (2011) 23(7): 1076-1086. https://doi.org/10.1061/(ASCE)MT.1943-5533.0000261

[28] J. Ma, F. Dehn, Schwind- und Kriechverhalten von Beton auf Basis eines alkalisch-aktivierten Hüttensands (Shrinkage and creep behavior of alkali-activated slag concrete, mainly in German). Betonund Stahlbetonbau. (2017) 112: 22-30. https://doi.org/10.1002/best.201600052

[29] Z. Li, J. Liu, G. Ye, Drying shrinkage of alkali-activated slag and fly ash concrete; A comparative study with ordinary Portland cement concrete. Heron (2019) 64: 149-163.

[30] H. Ye, A. Radlińska, Shrinkage mechanisms of alkali-activated slag. Cem Concr Res (2016) 88: 126-135. https://doi.org/10.1016/j.cemconres.2016.07.001

[31] G. Wang, Y. Ma, Drying shrinkage of alkali activated fly ash/slag blended system. Journal of Sustainable Cement-Based Materials (2018) 7: 203-213. https://doi.org/10.1080/21650373.2018.1471424

[32] M. Mastali, P. Kinnunen, A. Dalvand et al., Drying shrinkage in alkaliactivated binders - A critical review. Constr Build Mater (2018) 190 533-550. https://doi.org/10.1016/j.conbuildmat.2018.09.125
[33] M. Hojati, A. Radlinska, Shrinkage and strength development of alkaliactivated fly ash-slag binary cements. Constr Build Mater (2017) 150 808-816. https://doi.org/10.1016/j.conbuildmat.2017.06.040

[34] M. Hojati, F. Rajabipour, A. Radlinska: Drying shrinkage of alkaliactivated cements: effect of humidity and curing temperature. Mater Struct (2019) 52: 118-132 https://doi.org/10.1617/s11527-019-1430-1

[35] A. A. Melo Neto, M. A. Cincotto, W. Repette, Drying and autogenous shrinkage of pastes and mortars with activated slag cement. Cem Concr Res (2008) 38(4) 565-574. https://doi.org/10.1016/i.cemconres.2007.11.002

[36] F. Collins, J. Sanjayan: Effect of pore size distribution on drying shrinking of alkali-activated slag concrete. Cem Concr Res (2000) 30: 1401-1406. https://doi.org/10.1016/S0008-8846(00)00327-6

[37] H. Ye, A. Radlińska, Shrinkage mitigation strategies in alkali-activated slag. Cem Concr Res (2017) 101: 131-143. https://doi.org/10.1016/i.cemconres.2017.08.025

[38] Z. Li, N. Nedeljković, B. Chen, G. Ye, Mitigating the autogenous shrinkage of alkali-activated slag by metakaolin. Cem Concr Res (2019) 122: 30-41. https://doi.org/10.1016/i.cemconres.2019.04.016

[39] J. Kwasny, M. Soutsos, J. A. McIntosh, D. J. Cleland, banahCEM comparison of properties of a laterite-based geopolymer with conventional concrete. In: M. R. Jones et al. (Eds.), Proc. of 9th International Concrete Conference 2016: Environment, Efficiency and Economic Challenges for Concrete. University of Dundee (2016) 383-394.

[40] EN 196-1:2016 - Methods of testing cement - Part 1: Determination of strength. 2016

[41] EN 1015-3:2007 0301 - Methods of test for mortar for masonry- Part 3: Determination of consistence of fresh mortar (by flow table). 2007.

[42] ONR 23303:2010 0901 - Test methods for concrete - National application of testing standards for concrete and its source materials (in German), Austrian Standards International. 2010.

[43] EN 12390-6:2009 - Testing hardened concrete - Part 6: Tensile splitting strength of test specimens. 2009.

[44] fib (International Federation for Structural Concrete), fib Model Code for Concrete Structures 2010. Wilhelm Ernst \& Sohn, Berlin, 2013 https://doi.org/10.1002/9783433604090

[45] Schleibinger, Shrinkage-Drain. URL http://www.schleibinger.com/ ...Schwinden:Schwindrinne ... schwindrinne manual-1.pdf, accessed 28.07.2020.

[46] EN 12617-4:2002 0901 - Products and systems for the protection and repair of concrete structures - Test methods - Part 4: Determination of shrinkage and expansion. 2002.

[47] EN 12390-16: 2019 - Testing hardened concrete - Part 16: Determination of the shrinkage of concrete. 2019.

[48] Sobriety s.r.o., Mercury RT measuring system. URL https://www.sobriety.cz/uploads/PriNMoBInnmHWZ7nIEZ7ZO4QM c6ReVSc.pdf Accessed 28.07.2020.

[49] EN 196-3 EN 196-3 - Methods of testing cement - Part 3: Determination of setting times and soundness. 2016.

[50] EN 1770:1998 1001 Products and systems for the protection and repair of concrete structures - Test methods - Determination of the coefficient of thermal expansion. 1998.

[51] F. Collins, J. G. Sanjayan, Strength and shrinkage properties of alkaliactivated slag concrete containing porous coarse aggregate. Cem Concr Res (1999) 29(4): 607-610. https://doi.org/10.1016/S00088846(98)00203-8

[52] R. J. Thomas, D. Lezama, S. Peethamparan, On drying shrinkage in alkali-activated concrete: Improving dimensional stability by aging or heat-curing. Cem Concr Res (2017) 91: 13-23. https://doi.org/10.1016/j.cemconres.2016.10.003

[53] M. Mastali, P. Kinnunen, A Dalvand, R. Mohammadi Firouz, M Illikainen, Drying shrinkage in alkali-activated binders - A critical review. Constr Build Mater (2018) 190: 533-550. https://doi.org/10.1016/j.conbuildmat.2018.09.125

[54] H. Ye, A. Radlińska,. Shrinkage mechanisms of alkali-activated slag. Cem Concr Res (2016) 88: 126-135. https://doi.org/10.1016/j.cemconres.2016.07.001

[55] H. Ye, C. Cartwright, F. Rajabipour, \& A. Radlińska. Understanding the drying shrinkage performance of alkali-activated slag mortars. Cem Concr Compos (2017) 76: 13-24 https://doi.org/10.1016/j.cemconcomp.2016.11.010

[56] Z. P. Bažant, L. Cedolin, Stability of structures: Elastic, inelastic, fracture and damage theories. World Scientific Publishing Co. (2010). https://doi.org/10.1142/7828 
[57] Z.P. Bažant, Prediction of concrete creep and shrinkage: past, present and future. Nucl Eng Des (2001) 203 (1): 27-38 https://doi.org/10.1016/S0029-5493(00)00299-5

[58] H. Péron, Desiccation Cracking of Soils: THĖSE 4025. Dissertation. EPFL, École Polytechnique Fédérale De Lausanne (2008). 